The Oxford Handbook of Applied Linguistics Second edition

Edited by Robert B. Kaplan

The Oxford Handbook of Case

Edited by Andrej Malchukov and Andrew Spencer

The Oxford Handbook of Cognitive Linguistics Edited by Dirk Geeraerts and Hubert Cuyckens

The Oxford Handbook of Comparative Syntax

Edited by Guglielmo Cinque and Richard S. Kayne

The Oxford Handbook of Compounding

Edited by Rochelle Lieber and Pavol Štekauer

The Oxford Handbook of Computational Linguistics

$$
\text { Edited by Ruslan Mitkov }
$$

The Oxford Handbook of Compositionality

Edited by Markus Werning, Edouard Machery, and Wolfram Hinzen

The Oxford Handbook of Field Linguistics Edited by Nicholas Thieberger

The Oxford Handbook of Grammaticalization Edited by Heiko Narrog and Bernd Heine

The Oxford Handbook of Japanese Linguistics Edited by Shigeru Miyagawa and Mamoru Saito

The Oxford Handbook of Laboratory Phonology

Edited by Abigail C. Cohn, Cécile Fougeron, and Marie Hoffman

The Oxford Handbook of Language Evolution

Edited by Maggie Tallerman and Kathleen Gibson

The Oxford Handbook of Language and Law Edited by Lawrence Solan amd Peter Tiersma

The Oxford Handbook of Linguistic Analysis Edited by Bernd Heine and Heiko Narrog

The Oxford Handbook of Linguistic Interfaces Edited by Gillian Ramchand and Charles Reiss

The Oxford Handbook of Linguistic Minimalism Edited by Cedric Boeckx

The Oxford Handbook of Linguistic Typology Edited by Jae Jung Song

The Oxford Handbook of Translation Studies Edited by Kirsten Malmkjaer and Kevin Windle

\section{LINGUISTIC FIELDWORK}

Edited by

NICHOLAS THIEBERGER 


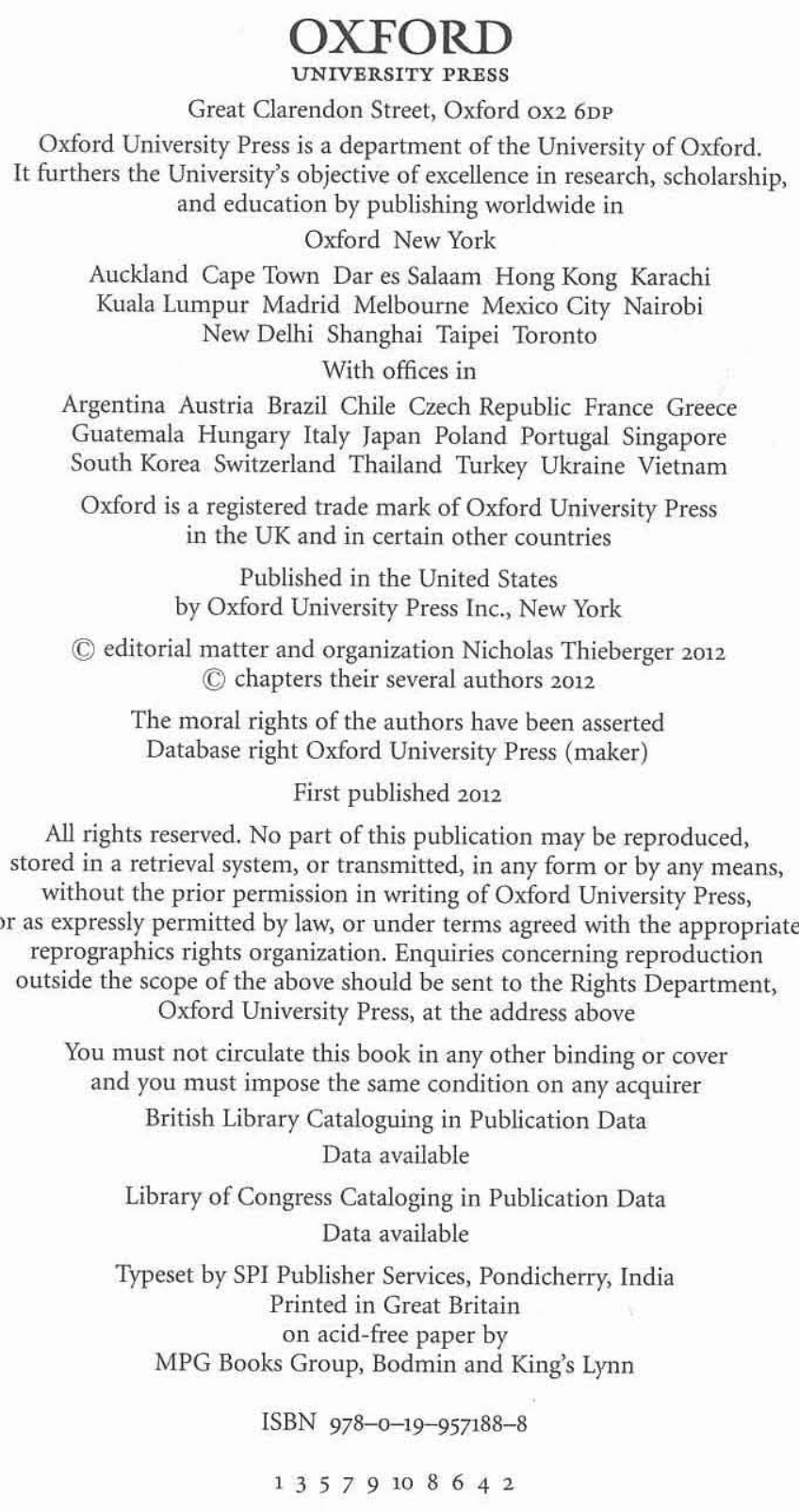

Introduction

Nicholas Thieberger

\section{PART I DATA COLLECTION AND MANAGEMENT}

1. Audio and Video Recording Techniques for Linguistic Research Anna Margetts and Andrew Margetts

2. A Guide to Stimulus-Based Elicitation for Semantic Categories Asifa Majid

3. Morphosyntactic Analysis in the Field: A Guide to the Guides Ulrike Mosel

4. Linguistic Data Management

Nicholas Thieberger and Andrea L. Berez

\section{PART II RECORDING PERFORMANCE}

5. Sociolinguistic Fieldwork

Miriam Meyerhoff, Chie Adachi, Golnaz Nanbakhsh,

and Anna Strycharz

6. Reasons for Documenting Gestures and Suggestions

for How to Go About It

Mandana Seyfeddinipur

7. Including Music and the Temporal Arts in

Language Documentation

Linda Barwick 
PART III COLLABORATING WITH OTHER DISCIPLINES

8. Anything Can Happen: The Verb Lexicon and Interdisciplinary Fieldwork

Nicholas Evans

9. Understanding Human Relations (Kinship Systems) Laurent Dousset

10. The Language of Food Nancy J. Pollock

11. Botanical Collecting Barry J. Conn

12. Ethnobiology: Basic Methods for Documenting Biological Knowledge Represented in Languages Will McClatchey

13. Technology Pierre Lemonnier

14. Fieldwork in Ethnomathematics Marc Chemillier

15. Cultural Astronomy for Linguists Jarita Holbrook

16. Geography: Documenting Terms for Landscape Features Andrew G. Turk, David M. Mark, Carolyn O'Meara, and David Stea

17. Toponymy: Recording and Analysing Placenames in a Language Area

David Nash and Jane Simpson

\section{PART IV COLLABORATING WITH THE COMMUNITY}

18. Ethical Issues in Linguistic Fieldwork Keren Rice
19. Copyright and Other Legal Concerns

Paul Newman

20. Training Linguistics Students for the Realities of Fieldwork Monica Macaulay

\section{References}

527

537 


\section{Notes ON CONTRIBUTORS}

Chie Adachi is a PhD candidate in Linguistics at the University of Edinburgh. Currently, she works on Japanese complimenting behaviour within the framework of (interactional) sociolinguistics for her $\mathrm{PhD}$ project. She is interested in how young Japanese speakers socially and linguistically construct the speech act of complimenting. She is also interested in the gendered nature of this speech act. Her study at Edinburgh is fully funded by the Ministry of Education, Japan, for three years.

Linda Barwick (Associate Professor, University of Sydney) is Director of PARADISEC, the Pacific and Regional Archive for Digital Sources in Endangered Cultures, established in 2003 by several Australian universities with support from the Australian Research Council. An ethnomusicologist with fieldwork experience in Australia, Italy, and the Philippines, she is interested in using digital technologies to extend access to research results by collaborating communities. Recent song documentation projects jointly undertaken with linguists include the Murriny Patha song project, the Western Arnhem Land song project, and the Iwaidja Project. Her publications include multimedia $\mathrm{CDs}$ and web resources produced in collaboration with singers and communities.

Andrea L. Berez is currently finishing her doctoral dissertation in the Department of Linguistics at the University of California, Santa Barbara. She is primarily a documentary and descriptive linguist specializing in Ahtna, an endangered Athabascan language spoken in south central Alaska. Her linguistic interests include geographic cognition, intonation, polysynthesis, and discourse, and she has been active in promoting and developing the technological infrastructure for language documentation and archiving.

Marc Chemillier is Director of Studies at the EHESS in Paris (School for Advanced Studies in Social Sciences). He received a $\mathrm{PhD}$ in Computer Science and also has degrees in Mathematics, Musicology, Philosophy, and Anthropology. He has conducted fieldwork among the Nzakara of Central African Republic to study their harp music, and in Madagascar to work on the ethnomathematics of divination. His main interests focus on the modelling of elaborated knowledge developed in oral tradition, thus associating fieldwork for the ethnographic recording of data and digital technologies for the modelling aspect of his approach. His recent research deals with musical knowledge and improvisation in collaboration with
IRCAM in Paris (Institute for Research and Coordination Acoustic/Music). He is the author of Les Mathématiques naturelles (2007).

Barry Conn is a Principal Research Scientist at the National Herbarium of New South Wales, Royal Botanic Gardens Sydney, and is an Associate Professor at the University of Sydney. He is a plant systematist with interests in the phylogeny of the Lamiaceae, Loganiaceae, and Urticaceae, and has published more than 190 research papers in scientific journals. Dr Conn has undertaken field studies throughout Australia and has worked extensively in the tropical forests of Indonesia and Papua New Guinea. He has maintained strong interests in electronic data, and has assisted with the development of international standards for the storage and transfer of electronic natural history database records.

Laurent Dousset is an anthropologist specializing in Australian Aboriginal cultures, and has recently also engaged in fieldwork in Vanuatu. His main interests are kinship and social organization, social transformations, and issues of landownership. Currently associate professor at EHESS (the School for Advanced Social Studies, Paris and Marseilles), he is director of CREDO (the Centre for Research and Documentation on Oceania, Marseilles) and has published numerous scientific papers on various issues in Aboriginal Australia. He also published two books, Assimilating Identities (Oceania Monograph, 2005) and Mythes, Missiles et Cannibales (Société des Océanistes, 2011).

Nicholas Evans is Professor of Linguistics at the Australian National University. He is a field linguist with wide expertise in language documentation and typology. After decades of work on Australian Aboriginal languages (especially Kayardild, Dalabon, Iwaidja, and Bininj Gun-wok), he has recently begun work on Papuan languages in Southern New Guinea, particularly Nen. He has published grammars of Kayardild and Bininj Gun-wok, dictionaries of Kayardild and Dalabon, and over 100 papers on a wide range of linguistic topics. In addition to scientific work, he has been extensively involved in returning his expertise to indigenous communities through vernacular-language educational materials, court interpreting, land and sea rights work, and cultural interpreting for indigenous artists.

Jarita Holbrook (Near Eastern Studies, University of Arizona) is the author of Following the Stars, a study of modern stellar navigation, and editor of African Cultural Astronomy (2008). Her research on humans and their relationship to the sky includes studies of indigenous people, the general public, and professional astronomers. She is currently working on a book investigating academic programs focused on increasing the number of minority astronomy doctorates. Currently, she is the youngest chair of the Historical Astronomy Division of the American Astronomical Society and the first African-American Vice President of the European Cultural Astronomy Society (SEAC). 
in 2005, where she continued her studies as a PhD student in Sociolinguistics. Her research looks at the interplay of linguistic and sociolinguistic norms of politeness portrayed with Persian address system. She is interested in the analysis of language and social interaction, specifically the intersection of language, culture, and society, using spontaneous interactions. Since September 2010 she has been a faculty member of Islamic and Middle Eastern Studies at the University of Edinburgh.

David Nash is Honorary Visiting Fellow in Linguistics, School of Language Studies, The Australian National University. He has published on Australian languages over the last three decades, including co-editing Language in Native Title (2002) and Forty Years On: Ken Hale and Australian Languages (2001), and has been a consultant for a number of claims to traditional land in Australia. He continues to be involved in the mapping of sites in the country of the Warlpiri and their neighbours in central Australia.

Paul Newman received his BA and MA from the University of Pennsylvania and his $\mathrm{PhD}$ (Linguistics) from the University of California, Los Angeles. He has held academic positions at Yale, Bayero University (Nigeria), University of Leiden (Netherlands), and Indiana University, where he is Distinguished Professor Emeritus. He has published eighteen books and over 100 articles and reviews. He is regarded as the world's leading authority on the Hausa language. Newman is also a lawyer (JD, summa cum laude, Indiana University). He was copyright specialist at the University of Michigan and Fulbright professor in law at the University of Haifa. He was formerly Special Counsel to the LSA.

Carolyn O'Meara is an assistant professor and researcher in the Seminario de Lenguas Indígenas within the Instituto de Investigaciones Filológicas at the Universidad Nacional Autónoma de México in Mexico City. She received her $\mathrm{PhD}$ in Linguistics from the University at Buffalo in 2010. She has been conducting fieldwork in El Desemboque, Sonora, Mexico, with the Seri people since 2004. Her interests include landscape classification (e.g. ethnophysiography/landscape ethnoecology) and semantics, including spatial reference and lexical semantics. She is currently extending her work on landscape classification in Seri to the larger domain of the structure of the nominal lexicon in Seri.

Nancy Pollock has retired from her position as Senior Lecturer in Anthropology and the later position as Acting Director of Development Studies at Victoria University of Wellington, New Zealand. Her research work on food security, health issues, and dietary change is derived from initial work in the Marshall Islands. This work was the basis for many publications on food issues, including These Roots Remain, and Social Aspects of Obesity, co-edited with Igor de Garine. She has worked on Nuclear Claims for Compensation post-Bravo in 1954, and also on Nauruan claims for compensation for the effects of mining phosphate on Nauru. She is currently completing a book on the social impact of mining on Nauru.
Keren Rice is University Professor and Canada Research Chair in Linguistics and Aboriginal Studies at the University of Toronto. She studies the Dene (Slavey) language of Canada's Northwest Territories, and has written on fieldwork and on ethics in linguistic fieldwork.

Mandana Seyfeddinipur is a senior research fellow and the director of the Endangered Languages Documentation Programme of the Hans Rausing Endangered Languages Project at the School for Oriental and African Studies (SOAS). Her main research interest is the visual mode of language, especially gestures, language use, and the psychology of language. She has worked on Azerbijanian and Iranian gesture use, and on the integration of disfluent speech and gesture.

Jane Simpson is Chair of Indigenous Linguistics, School of Language Studies, The Australian National University. She has studied Australian Indigenous languages for more than three decades, acted as a consultant on land claims, and co-edited The Land is a Map: Placenames of Indigenous Origin in Australia (2002) and Children's Language and Multilingualism: Indigenous Language Use at Home and School (2008).

David Stea received a BSc (hons) in Mechanical/Aeronautical Engineering from what is now Carnegie-Mellon University, an MSc in Psychology from the University of New Mexico, and a PhD in Psychology from Stanford University. He is Professor Emeritus of Geography and International Studies, Texas State University, San Marcos, and Research Associate, Centre for Global Justice (Mexico). A cofounder of the field of environmental psychology, his research interests include spatial cognition, map learning in young children, participatory planning with Indigenous peoples, and sustainable development. He has written several books, including Image and Environment, Maps in Minds, Environmental Mapping, and Placemaking.

Anna Strycharz is a PhD student at the University of Edinburgh. Her research interests focus around language variation and change in Japanese, especially in the area of honorifics in the dialect of Osaka. She has lived, worked, and conducted fieldwork in Japan.

Nicholas Thieberger wrote a grammar of South Efate (central Vanuatu) arising out of a media corpus he built in the course of his fieldwork. In 2003 he helped establish the digital archive PARADISEC (paradisec.org.au) and is a co-director the Resource Network for Linguistic Diversity (RNLD). He is interested in developments in e-humanities methods and their potential to improve research practice, and he is now developing methods for creation of reusable data sets from fieldwork on previously unrecorded languages. He taught in the Department of Linguistics at the University of Hawai'i at Mānoa and is now an Australian Research Council QEII Fellow at the University of Melbourne. 
C H A P T E R 8

\title{
ANYTHING CAN HAPPEN
}

\section{THE VERB LEXICON AND INTERDISCIPLINARY FIELDWORK}

\author{
NICHOLAS EVANS
}

\subsection{INTRODUCTION ${ }^{1}$}

The centrality of language in human life means we cannot document any language without understanding all the spheres of knowledge it is used to talk about. Equally, undocumented languages contain too much information to be wasted on linguists alone. As the medium through which the whole fabric of traditional knowledge about everything in the world is transmitted, the importance of these languages stretches out in the direction of many fields of enquiry, from ethnoecology to comparative jurisprudence to deep history to the study of musical and

${ }^{1}$ I would like to thank all of those who have helped me understand Iwaidja, either as speakers or as fellow outsider-investigators: Kim Akerman, Reuben Arramunika, Linda Barwick, Archie Brown, Bruce Birch, Murray Garde, Illyjilly, Rae Kirribuk, Ronald Lamilami, Khaki Marrala, David ('Cookie') Minyimak, Ruth Singer, Amos Teo, †Charlie Wardaga, Joy Williams, †Brian Yambikbik, and Mary Yarmirr, as well as two anonymous reviewers of an earlier version of this chapter. 
verbal art. Linguists, then, have a responsibility not just to their own field but to all areas of scholarship concerned with the almost infinite varieties of human creativity, and we abrogate this responsibility if we do not seek to follow our documentation of the languages we study down all these lanes and byways of orally transmitted lore.

But, as we struggle to learn a field language and talk to the people who speak it about what matters in their lives, we quickly become aware of how narrow are the boundaries of our knowledge. Whether we fail to identify a local plant or animal species, can't figure out how to describe special ways of tying up roof thatch, or ask dumb questions about mystifying ethnographic details, we risk foreshortening our investigations because-in the words of Ralph Bulmer's Kalam teacher who explained why they hadn't bothered to give him the sort of nuanced terminology for rocks which they had for plants_- why should we waste our time telling you something you couldn't possibly understand?'2

One of the appeals of fieldwork is that we get the opportunity to develop interests in many new subjects, from botany through ethnography to thatchmaking. ${ }^{3}$ But few linguists reach the point where we are able to really penetrate to the heart of all these fields, and in practice the best way to extend our documentary coverage is through some form of interdisciplinary fieldwork. The linguist can then work in concert with experts who can pose the right questions to engage the deep knowledge that speakers have of particular areas. The same Kalam people who had fobbed Bulmer off with a single word, purportedly for all kinds of rock, readily gave his geologist colleague John Chappell a long and nuanced list, because 'your friend's questions showed that he does know about rocks'.

Some form of interdisciplinary collaboration in fieldwork, then, is essential to coaxing out a full encyclopedic coverage of the fine-grained categorizations of its culture and environment which any language contains. In this chapter I show how this can happen in practice, drawing on the efforts myself and a number of colleagues to document an Australian Aboriginal language, Iwaidja.

To put scientific flesh on the procedural bones of my argument, I will use a specific semantic problem to integrate the case studies I will use in this chapter: the problem of recording a detailed verb vocabulary. In the rest of this section I briefly sketch a range of approaches to interdisciplinary fieldwork, and then give relevant background on the Iwaidja language documentation project. In \$8.2 I consider the general problem posed by event-denoting expressions-typically realized as

${ }^{2}$ Diamond (1991); Evans (2010: 111).

See Franchetto (2006) for an excellent overview of the main ethnographic issues that linguists should attend to in language documentation, and Haviland (2006) on analytic and elicitation techniques for documenting lexical knowledge. verbs-for semantic typology. In $\$ 8.3$ I set up three particular grammatico-semantic problems posed by the verb lexicon in Iwaidja: the unusually high proportion of verbs in the lexicon, the analytic difficulties posed by a degenerate and partially fossilized system of double argument agreement across (originally) five genders, and the large number of long and (at least initially) apparently unanalysable verb stems. In §8.4 I illustrate how interdisciplinary fieldwork taking in a range of other disciplines or contingencies driving particular types of data connection-material culture, musicology, linguistic anthropology, art, medical expressions, tida terms-ended up serendipitously providing data that allowed us to make progress with the problems set up in §8.3. Finally, I draw together these threads into a conclusion in $\S 8.5$.

\subsubsection{Strategies for interdisciplinary fieldwork}

Interdisciplinary fieldwork involving linguists can take many forms, including:

(a) the 'expedition strategy', where a large group are all present in the fieldsite for a lengthy period of time; ${ }^{4}$

(b) the 'partner strategy', where a couple carry out long-term fieldwork in a community, one specializing in language and the other in some other issue (e.g. ethnobotany, kinship);

(c) the 'guest expert' strategy, where a linguist engages in long-term fieldwork in a community, bringing in a range of disciplinary specialists for dedicated shorter-term investigation of particular topics (e.g. botany, material culture music) in the company of the linguist;

(d) the 'long-haul team' strategy, where an investigator specializing in one field then places one or more students who can deal with other topics-an example being the team established by anthropologist Ralph Bulmer, initially recruiting linguist Bruce Biggs and subsequently linguist Andy Pawley, though this team also made notable use of trained native speakers like Saem Majnep and shorter-term guest experts like biologist John Dumbacher and geologist John Chappell.

Each of these strategies (and many other hybrid possibilities) has its own advantages and disadvantages. The choice between them in a particular case will depend on many factors, such as who is available, what funding support can be obtained, personality of the linguist, and so forth, so I will not adjudicate on the relative merits of these strategies here. I do believe, though, that in all cases it is

${ }^{4}$ A famous example being the Cambridge Anthropological Expedition to the Torres Strait, led by Alfred Cort Haddon, in 1898, which produced a 6 -volume report covering most ethnographic topics, including language. 
crucial that the linguist have enough 'solo time' in the course of their investigations that they can immerse themself in the language and deal directly with its speakers on a one-to-one basis. Otherwise they will find it difficult to acquire the fluency and internalized understanding of the language that is their single greatest research asset. And it is this fluency in the language that allows the field researcher to be a true participant observer, which remains the best way of ensuring that it is the speech community's own practice and expertise, rather than the question-agendas of outside experts, which find their way into a fully rounded understanding of the language.

The advantages of interdisciplinary fieldwork are most obvious in the way it can extend the detailed lexicon of targeted areas-botanical terms with the botanist, rock types with the geologist, terms for spear or personal adornment types with the material culture specialist, and so forth.

The history of interdisciplinary collaboration in field linguistics goes back a long way. An early and particularly illustrious case was the work of Fray Bernardino de Sahagún on Aztec in the mid-sixteenth century in compiling the General History of the Things of New Spain, also known as the Florentine Codex, and arguably the world's first proper ethnography. Originally this was written down in Aztec, then translated into Spanish, and now it is available in English as well (Sahagún 1970), thanks to the translation by Dibble and Anderson. Sahagún's team of Aztec scribes enlisted the expertise of local chiefs and leaders, as well as painters able to portray customs and costumes, enabling him to record a vast panorama covering just about every facet of life from religion to marriage arrangements to the appropriate ways of dealing with errant youths. Revealingly, Sahagún regarded the whole sixteenvolume masterpiece as 'a dragnet to bring in all the words of the language with their meaning'.

A danger of exclusively emphasizing this motivation, however, is that some field linguists simply do not see the compiling of a comprehensive lexicon as part of their core interests - or, at best, see it as a chore rather than a research priority. For this reason, in this chapter I will concentrate on the advantages that interdisciplinary fieldwork can bring to our understanding of the workings of a central grammatical domain outside the specialist areas being directly investigated-event descriptors, typically verbs, that describe what can happen within a given word-world. These are not generally the primary target of investigation by interdisciplinary partners, but from the linguist's point of view are a central and puzzling part of the grammar-lexicon interface. I will show how the investigation of the verb lexicon can be advanced on many fronts, in large part to the rich data thrown up as a by-product of interdisciplinary work in other, targeted domains.

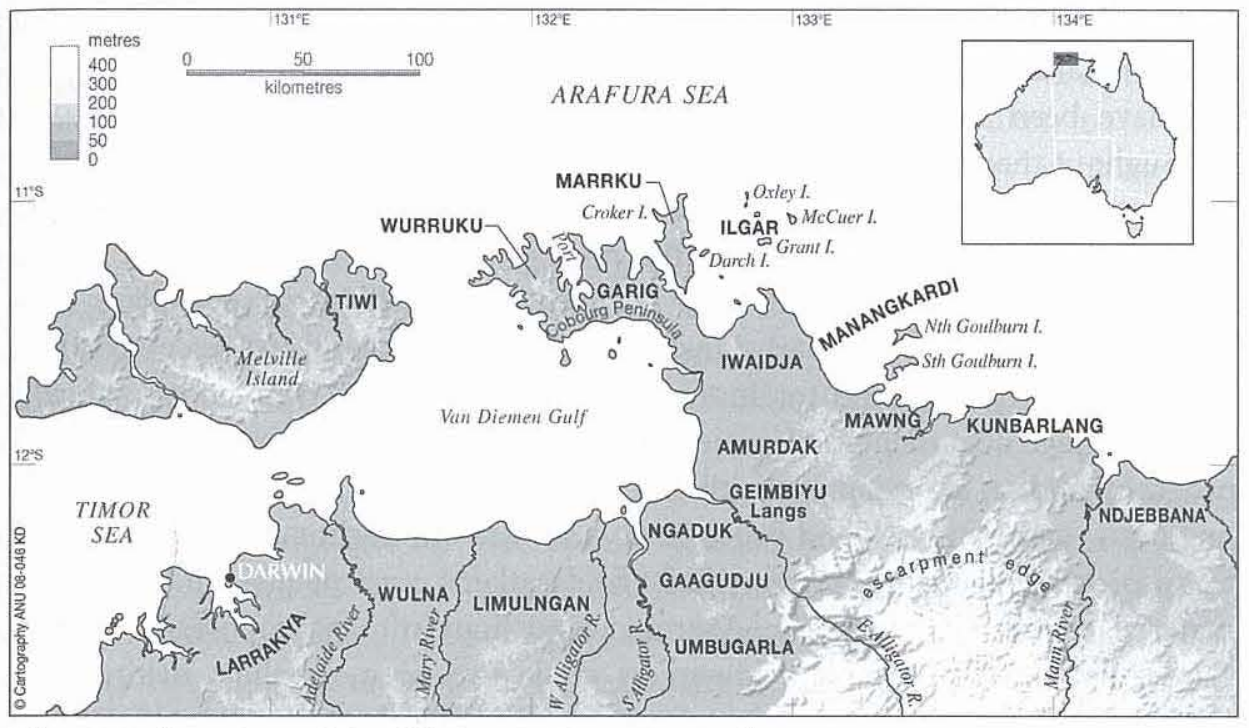

Map 8.1. Location of Iwaidja in northern Australia

\subsubsection{The Iwaidja language documentation project}

The series of case studies in this chapter will draw on my experiences carrying out interdisciplinary fieldwork on Iwaidja (see Map 8.1), a non-Pama-Nyungan language of Croker Island and the Cobourg Peninsula, Arnhem Land, Northern Territory (Evans 2000a), now spoken by perhaps 150 people, though fewer than 30 still command the full richness of the language. Iwaidja speakers dwell in a region of great multilingualism, with an ideology that ties land to clan identity to distinctive linguistic varieties (see Evans 2010: 5-9).

Typically, Iwaidja speakers also know the closely related language Mawng from Goulburn Island (Capell and Hinch 1970; Singer 2007), the language Bininj Gunwok $^{6}$ (Evans 2003) from the Gunwinyguan family to the south which serves as a regional and ceremonial lingua franca, English, and-among the older people, though most such people have passed away in the last few years-one or more of the highly endangered other languages of the region (Ilgar, Amurdak). Though Iwaidja speakers have now adopted many of the material trappings of Western culture-motorboats, cars, houses, videos-traditional ceremonial life remains strong, drawing in the wide network of relationships of intermarriage and other

\footnotetext{
5 Earlier spelt Maung.

${ }^{6}$ Also spelt Bininj Kun-wok, depending on which dialect's orthography is being used.
} 
kin ties that link people across scores of clans and dozens of languages in Western Arnhem Land.

I have been working on this language, on and off, since the early 1990s. Throughout that period I have interacted with various types of other investigator. Early on in my engagement with the language, my non-linguist colleagues were lawyers and anthropologists during the preparation of the Croker Island Native Title claim in the mid-199os. ${ }^{7}$ This involved the checking of vocabulary in a number of domains, particularly kinship, social structure, land and sea ownership, and terms for hunting and traditional food-divisions. Later, from 2003 to 2007 , I led a language documentation project, funded by the Volkswagenstiftung's DoBeS program $^{8}$ and set up on an explicitly interdisciplinary basis. In addition to the two linguists-namely myself and Bruce Birch, who was our anchor-man in the fieldthis project involved three primary guest fieldworkers: musicologist Linda Barwick, material culture specialist Kim Akerman, and linguistic anthropologist Murray Garde. Each of these guest fieldworkers made two or more short fieldtrips to Croker Island and its surrounds, accompanied by Birch and/or myself. During these trips we carried out detailed investigations of their areas of interest, resulting in products such as recordings of song series (see Barwick et al. 2005; Barwick, Birch, and Evans 2007) and inventories of material culture (see Akerman 2007). The project was also able to enlist the skills of art historian and photographer Sabine Hoeng, who has now begun a $\mathrm{PhD}$ on the history of art in the region but also worked with Birch on the compilation of several posters for community use showing traditional knowledge of shellfish, fish, and plants (Birch et al. 2005; 2006a; 2006b; 2007) and in the preparation of a medical phrase book to assist visiting medical personnel (Marrala et al. 2008). We also brought in a range of biologists from the Northern Territory museum who were able to assist with plant, shellfish, fish, and turtle identifications.

\subsection{The ElUSive VERB LEXICON}

Marianne Mithun (2007b: 32) has pointed out: 'The process of elicitation does tend to reap many more nouns than verbs.' There are many reasons for the difficulty of eliciting verb vocabulary. They include the greater complexity

${ }_{8}^{7}$ See Evans (2002a) for an account of the role of linguist in this claim.

${ }^{8}$ Yiwarruj, yinyman, radbiyi lda mali: Iwaidja and Other Endangered Languages of the Cobourg Peninsula (Australia) in their Cultural Context. Funded from 2003 to 2007 by the Volkswagen Foundation's DoBeS program. I would like to take this occasion to express my gratitude to the Volkswagen Foundation for their far-sighted and generous support of this research. involved in showing visual prompts for events rather than entities, and the fact that many investigators (e.g. taxonomic biologists) don't tend to think of asking for them. But perhaps most important is the fact that they are likely to be the most cross-linguistically variable part of a language's vocabulary in terms of denotation. This makes it difficult to know in advance what to ask for on the basis of previously studied languages. To make matters worse, the fact that so many grammatical problems are intimately tied up with the grammatical and semantic structure of verbs means that falling short on your event lexicon can hold you back from understanding central architectural issues in the grammar you are dealing with.

As an initial example, consider the rich set of terms in Bininj Gun-wok and other Central Arnhem languages for macropods-kangaroos and wallabies. Some dialects of Bininj Gun-wok-Gun-djeihmi and Kunwinjku—are spoken not far to the south of Iwaidja in Kakadu National Park, and partly due to this, work by biologists and anthropologists interested in Western Arnhem Land flora and fauna had assembled fairly comprehensive species lists by the mid 1980s (Altman 1981; Chaloupka and Giuliani 1984; Russell-Smith 1985). These included terms for all macropod species living in the area, including distinct terms for adult males, adult females, and young. For the antilopine wallaroo (Macropus antilopinus), for example, there are the terms karndakidj (adult male), karndayh (adult female), and djamunbuk (juvenile), as well as kalaba for an exceptionally large adult male. And for the agile wallaby (Macropus agilis) the adult male is warradjangkal or kornobolo, the adult female is merlbbe, and the juvenile is nakornborrh (there is also a baby term, nanjid). The existence of such triple sets is familiar from English sets like stallion/mare/foal and stag/doe/fawn.

What these lists did not pick up, however, was the existence of an additional set of verbal terms for the distinctive hopping or gait of most macropod types, which extends in most cases to distinctive verbs for the male and female gaits. A subset of these terms is given in (1):

(1) Mayali macropod terms (subset)
barrk male black wallaroo
barrk male black wallaroo

djugerre female black wallaroo

murlbardme hop (of black wallaroo)

garndagidj male antilopine wallaroo

mawudme hop (of male antilopine wallaroo)

garndalbburru female antilopine wallaroo

djalwahme hop (of female antilopine wallaroo)

gornobbolo male agile wallaby

merlbbe female agile wallaby

lurlhlurlme hop (of agile wallaby)

Macropus bernardus

Macropus antilopinus

\section{Macropus agilis}

Though documentation of the animal names was almost complete by the mid1980s, the existence and extent of the hopping verb set did not begin to get 
comprehensive documentation until the late 1990s, thanks to Murray Garde's very thorough participant-observation-based fieldwork. This included substantial involvement in hunting trips where remarks about gait turned out to be a crucial step in identifying macropod types. In this case the initial identification of the noun terms had been carried out by teams working in close collaboration with biologists, while the verb terms came later through more purely linguistic work. This example illustrates, incidentally, the importance of participant observation in throwing up material that may be overlooked in elicitation or lines of questioning that draw on disciplinary expert's beliefs about preexisting categories. But my main point at this stage is to illustrate that there was a significant time-lag between recording the nominal and the verbal terms in the same vocabulary domain.

Before continuing, it is worth spelling out three key assumptions about language documentation, and in fact about linguistic fieldwork more generally:

(a) It aims for as complete, accurate, and emic ${ }^{9}$ lexical coverage as possible.

(b) Not all domains are equally easy to elicit.

(c) Ease of elicitation will reflect, among other things:

- The 'exhibitability' of stimuli, e.g. by ostensive elicitation (pointing at body parts, or colouring them in to show their extent on a drawing of a body $y^{10}$ ) or by showing pictures of birds, or playing recordings of bird or frog calls.

- The degree of isomorphism to contact language(s), in the case of translational elicitation. No great semantic harm is done if an English speaker gets the German or Russian words Bruder or brat by asking for the translation of 'brother', but if I do this for Kayardild ${ }^{11}$ I will likely end up with one or more inexact translations: thabuju (older brother; male speaker), duujinda (younger brother; male speaker), or kularrinda (brother of female speaker, but also sister of male speaker).

- Word class can affect the ease of semantic determination. The simpler a word's morphological possibilities, the easier it will be to obtain, and it is also easier to identify the semantic contribution of the lexical stem and disentangle it from the contributions of a range of inflectional material. Since verbs tend to be the morphologically most complex part of a language's lexicon, this adds an additional layer of difficulty to their relative non-exhibitability.

9 I.e. it captures the language's concepts on their own terms, as far as possible, rather than simply seeking translation equivalents from some contact language.

${ }_{10}$ See Enfield, Kita and de Ruter (2006) for the advat unexpected 'cuts' in the extent of body part terms.

nexpected 'cuts' in the extent of body part terms. Kayardild is another Aboriginal language, not related to Iwaidja except at the deepest level, and spoken many hundreds of $\mathrm{km}$ to the east, in what is effectively a different social universe, though it shares significant principles of kinship semantics with Iwaidja. See Evans (1995).
- High-frequency lexical items are easier to detect and define. Excerption from text material is one of the best checks on what a word means, so the more frequently it occurs the more reliable the data is.

Verbs can be difficult to elicit and understand for all but the last of the above reasons. They are hard to exhibit (try imitating the hopping of a female rock wallaby!), generally show limited isomorphism across languages, and belong to a word class that tends to have more complicated morphology than others. But interdisciplinary investigations have the potential to ramp up the likelihood of occurrence of particular verbs in particular domains, thus getting the frequency factor on side, or at least condensing enough discussion on particular topics to give them a chance of showing up in the corpus.

\subsection{Verbs in the IWaidja lexicon: THREE ISSUES}

the set of nouns in a language is always much larger than the set of verbs (Foley 1986: 113)

In this section I discuss three special problems posed for the analysis of Iwaidja grammar and vocabulary by the way it organizes its verb lexicon. This will set the scene for the case studies that I will discuss in $\$ 8.4$, where I show how particular discoveries thrown up as a by-product of interdisciplinary fieldwork have helped us make progress with these three problems.

\subsubsection{Lexicalization in a verby language}

Iwaidja is a very 'verby' language-verbs are around 40 per cent of the lexicon, roughly around the same figure as for nouns. Compare this with English, where the ratio of nouns to verbs is greater than 5:1 on some counts (Chang et al. 2002), or with another Australian language, Kayardild, where nouns outnumber verbs by more than 2:1 (figures calculated from Evans 1992), or with languages like Kalam which are normally described as having barely 100 verb lexemes ${ }^{12}$ - of which as few

${ }^{12}$ As opposed to complex coverb + verb collocations, of which there are thousands, raising the question of what the relevant unit is for comparison, but the figures given above have been widely quoted. 
as 15 account for 89 per cent of verb occurrences in text, and 35 for 98.6 per cent of all verb tokens (Pawley 1993: 87).

It has sometimes been asserted that polysynthetic languages encode a greater proportion of their lexicon by verbs than is the case in other languages (Sasse 1988; Mithun 1996). Iwaidja, however, is not a polysynthetic language, although it is definitely head-marking. Verbs agree with up to two arguments by prefix and have some other verbal morphology (basically for direction and TAM). But they do not show the exuberant growth of applicatives, adverbial affixes, and open sets of incorporable nominals that are found in the polysynthetic languages like Bininj Gun-wok which border them to their south. In this sense, it would be misleading to see the proportion of the total lexicon represented by verbs as directly proportional to the degree of morphological complexity in the verb, since Bininj Gun-wok has more complex verbs but they take up a smaller proportion of the lexicon (around 27 per cent, against 62 per cent for nouns) ) $^{13}$ (And indeed, before we can test how well the correlation holds between verbal synthesis and the percentage of verbs in the lexicon, we need to get reliable figures on the number of verbal lexemes in the languages in the sample, which we can then cross-tabulate against other typological measures-emphasizing the need to make sure we get good coverage of the verbal lexicon.)

There could be a number of reasons for the swelling of the verbal lexicon in a language like Iwaidja:

(a) Concepts represented by nouns in other languages are represented by verbs instead, with scant change to the actual semantics.

(b) The defining features of holophrastic situations are construed differently, with more of an emphasis on event characteristics than entity characteristics.

(c) Situations are often described using highly specific denotations that incorporate reference to entities as well as processes.

(d) Some kinship relations may be characterized by verbal expressions, particularly in situations that are sensitive to speaker-addressee relations promoting a number of circumlocutions.

We shall see in $\$ 8.4 .1$ that each of these reasons plays a role in boosting some part of the Iwaidja verb lexicon.

\subsubsection{A degenerate gender agreement system on the verb?}

The ancestor language, proto-Iwaidjan, had a system of five genders (masculine, feminine, vegetable, neuter, land, and liquids ${ }^{14}$ ——still preserved in Mawng. Verbs

${ }^{13}$ Figures calculated from Garde’s (1997) electronic dictionary of the Kuninjku dialect.

${ }^{14}$ This is the term used by Singer (2007) for the corresponding gender in Mawng; etymologically it corresponds to the $k u / k u n$-marked gender in many other north Australian languages. agreed with both subjects and objects in gender. However, in Mawng around 35 per cent of verb lexemes have the gender of one or both morphological argument positions fixed in a system of 'lexicalised agreement' (Singer 2007), indicating that the agreement system built in a lot of 'pseudo-arguments'-something like expletive it in English he carked $i t^{15}$ but with more choices for gender and argument position (Evans 2007).

On the basis of material available in the mid-1990s, I concluded (Evans 1998), that Iwaidja had generalized one gender (the neuter) at the expense of al others, retains traces of some others in some verbs with lexicalized agreement (vegetable and land and liquids objects and intransitive subjects, and feminine and masculine transitive subjects with neuter objects), but only a small minority of possible combinations are exemplified. We shall see below that a more extensive sampling of the verb lexicon unearths evidence for a much wider range of combinations.

\subsubsection{Morphological opacity of verb stems}

Two shortish grammars of Iwaidja had been published before the DoBeS project began-Capell (1962) and Pym and Larrimore (1979). Neither mentions anything about the internal structure of the verb stem, for the good reason that recurring elements are very difficult to find. As a language learner it can be difficult to master large numbers of long stems without any evident internal logic of composition.

Verb stems are long, and lack obvious segmentability once inflectional and derivational suffixes have been peeled off:

\section{$(2 \mathrm{a})^{16}$ nanal $^{\mathrm{r}}$ aurarama iwaca nganaldaharrama Iwaja \\ 'I will speak Iwaidja' \\ na- '1sg.intrans.subject', -na 'irrealis': leaving l'auarama 'talk'}

(2b) natpal ${ }^{\mathrm{r}}$ akpuliwakpancil ${ }^{\mathrm{r}}$ in ngadbaldakburliwakbanjildin

${ }^{15}$ As in 'He'd always bragged about carking it before he hit twenty. When he turned twenty, he escalated the date of his demise to twenty-five' (Kathy Lette 1989: 86). Wiktionary defines this term as 'Australian, New Zealand slang for "to die"', and suggests cark may derive from carcass. Sarah Barret (p.c.) suggests the etymology might go back further, to an obsolete West Country dialect word quark, meaning the noise someone makes when being strangled, found e.g. in the name of a Somerset house, Quarkhill, built close to a crossroads where the notorious Judge Jeffrey hanged several people involved in the Monmouth rebellion in the 17 th century.

${ }_{16}$ At this early stage of the chapter I give examples using both IPA symbols and the practical ${ }^{16}$ At this early stage of the chapter I give examples using both IPA symbols and the practical orthography, which includes many digraphs; later in the paper I will simply use the practical orthography. I will also refrain from interlinearizing examples in these early sections, to encourage the reader to analyse their way into the language. The $\mathrm{l}^{\mathrm{r}}$ (ld in practical orthography) represents a latera with flapped release. 
'we two are going to have a yarn'

Inflectional and derivational elements:

jat- ' 1 st plural exclusive', pa- 'irrealis', -kpa 'dual', -ncil'i- 'reciprocal',

-n 'non-past', leaving $l^{r}$ akbuliwa 'have a yarn'

In these two verbs, it is tempting to posit an initial $\mathrm{l}^{\mathrm{r}}$ a or $\mathrm{l}^{\mathrm{r}} \mathrm{ak} \sim \mathrm{l}^{\mathrm{r}}$ as meaning 'word' or 'mouth' or 'tongue'-cf. the Bininj Gun-wok verb wokdi 'speak', which can be decomposed into the noun root wok 'language' and the verb di 'stand'. But there is little evidence for such a morpheme, except in these forms. The Iwaidja noun for 'word, language' is inman, the nominal root for 'tongue' is jaralk. The only glimmer of possible cognacy is the word $\mathrm{l}^{\mathrm{r}}$ akbiric for 'mouth; lips', which looks like it might be an old compound containing $\mathrm{l}^{\mathrm{r}} \mathrm{ak}$ as its first element, but the correspondence is less clear than one would wish.

The difficulty of decomposing verb stems in Iwaidja contrasts starkly with the situation in Bininj Gun-wok just to its south. Consider how you say 'he has a headache' in the two languages. In Iwaidja (2), the verb stem natpanpu (ngartbanbu) simply means 'have headache' or, more carefully, 'OBJ has a headache', lit. 'it headaches him', since the verb takes an experiencer object (Evans 2004). It is likely that this verb contains a segment $p u$ 'strike' etymologically, but there are no evident recurrences of a morpheme natpan in the corpus, and the root for 'head' is the unrelated -waual.

(3) ¿ijatpanpun

Iw ri-ngartbanbu-n

3sg.m.A $>3$ ss.f.O -head.aches-NPst

'She/He has a headache."17

In Bininj Gun-wok, by contrast, most verb lexemes readily yield to segmentation into crisply defined morphemes (3). There are practically no morphophonemic changes, and almost every element is attested elsewhere as the sole lexical morpheme in a word, so that its meaning can be easily isolated and its contribution to the verbal lexeme identified.

$\begin{array}{lllll}\text { (4) } & \text { ka-kodj-ngarrkme- } \varnothing & \text { [cf. } k \text { kn-kodj // } & \text { Vngarrkme // } & \text { ka-ngarrkme- } \varnothing \text { ] } \\ \text { BGW } & \text { 3sgSubj-head-suffer-NPst } & \text { IV-head } & \text { suffer } & \text { 3sgSubj-suffer-NPst } \\ & \text { 'He has a headache.' } & \text { 'head' } & \text { 'suffer' } & \text { 'He suffered' }\end{array}$

Morpheme identification basically depends on the presence of multiple combinations. Would a larger corpus reveal recurrent elements that would allow us to segment such verbs? We return to this question in the next section.

${ }^{17}$ Non-standard glosses are: A (transitive subject), f (feminine) m (masculine), NPst (non-past), $\mathrm{O}$ (object), ve (vegetable gender). Noun classes (Bininj Gun-wok): IV (basically neuter).

\subsection{Some EXAMPLES OF INTERDisciplinary FIELDWORK IN THE IWAIDJA PROJECT AND OF HOW THEY BUILT UP THE VERB LEXICON}

Having posed the three analytic problems in the preceding section-all unsolved at the time we began the Volkswagen project-I will now go through each of them, bringing in data largely gathered as a result of various interdisciplinary inquiries, and show how the rich haul of verb lexemes that these threw up as a by-product have helped us to furnish answers.

\subsubsection{Semantics of verbal expressions}

Some explanation is required if the proportion of the lexicon made up of nouns and verbs varies radically from one language to another (cf. \$8.3.1, 'Lexicalization in a verby language'). As it turns out, the verbiness of the Iwaidja lexicon seems to reflect a number of logically distinct factors, corresponding to the questions posed in $\S 8.3 .1$, which I now examine one at a time.

8.4.1.1 Are concepts represented by nouns in other languages represented in Iwaidja by verbs instead or as well as nouns?

An affirmative answer to this question implies that, for some concepts at least, the meaning expressed by the sign is independent of its combinatorics, i.e. of whether it is a noun or a verb.

One part of the Iwaidja lexicon gives a clear 'yes' answer to this question: the kinship vocabulary. Alongside 'normal' nominal kin terms like bunyi 'father, father's brother' and makamaka '(paternal) aunt', Iwaidja has verbal kin terms like mardyarrwun 'be father or father's sibling of; be first-generation ascending patrilineal relative of' (see Evans 200ob; 2006a). These take the senior kin as their subject, and the junior kin as their object, and make explicit the fact that kinship terms are relational, two-place predicates. Note in passing that the English verb 'to father' is not a good parallel, for a variety of reasons: (a) it focusses on the act of begetting rather than the kinship relation; (b) it cannot be used with female subjects in the way mardyarrwun can in a word like nganngamardyarrwun 'my paternal aunt, lit. (the female such that) she is (like a) father to me'; (c) it does not generalize to other kin, so there is no English verb 'to paternal grandfather' comparable to the Iwaidja verb ldakbaminy. 
The semantic difference between nominal and verbal kin terms in Iwaidja is slight. It boils down to two main points:

(a) Kinship verbs have a wider range of referents-e.g. the verb mardyarrwun can have a man (father or father's brother) or a woman (father's sister) as subject whereas the noun bunyi can only have a man as its referent. This is a general characteristic of kinship verbs that sometimes contrasts with kinship nouns but not always (e.g. in the grandparent generation both nouns and verbs span cross-sex sibling links), and it is not hard to find examples of kinship nouns in other Australian languages that exhibit comparable semantic ranges (e.g. in Kayardild the word kajakaja 'daddy' can also be used to refer to one's father's sister).

(b) Kinship verbs are always 'downward pointing', i.e. they have meanings like 'be older sibling to', 'be father to', or 'be grandparent to', but never 'be younger sibling to' or 'be child of'-though inflected verbs can achieve such reference by forming relative clauses off their objects: 'the one such that I am older sibling to her' for 'my younger sister'. By contrast, there are many nouns that designate kin relations from the junior perspective, such as ngawiny 'child of man'. This restriction to downward-pointing terms is unusual in systems of nominal kin terms, both cross-linguistically and in Australia, but is attested for Somali (Serzisko 1983).

Looking at the overall differences between nominal and verbal kin terms, then, they exist but are rather trivial and do not reflect different 'cuts' in the world. Rather, they are an economization of the verbal lexicon that takes advantage of two features of their inflectional potential which allow the number of lexemes to be reduced. The existence of a gender distinction for subject prefixes allows the difference between e.g. 'father' and 'paternal aunt' to be expressed inflectionally rather than by a different root (cf. rimardyarrwun 'his/her father', ri- 'he $>$ him/her', kamardyarrwun 'his/her paternal aunt', $k a$ - 'she $>$ him/her'), and the possibility of forming referring expressions of either the subject or object allows either the senior or the junior kin term to be taken as referent, again allowing the system to get away with having just downward-pointing roots: nganimardyarrwun 'my father', lit. 'the one such that he is father to me' vs. abardyarrwun 'my son', lit. 'the one such that I am father to him'. For the realm of kinship, then, the decision about whether to encode as noun or verb does not appear to result in a significantly different conceptual structure.

8.4.1.2 Are holophrastic situations construed differently, with more of an emphasis on process than entities, at least in some cases?

I demonstrate the affirmative answer to this question for Iwaidja by consideration of two semantic domains: clothing/wearing, and tides. (i) Clothing terms vs. wearing verbs. One of our goals in the Iwaidja project was to elicit a detailed material culture inventory together with a set of material culture terms, including terms for items of clothing and body decoration. As part of preparation for our first joint field trip, Kim Akerman prepared a set of photographs showing all known material culture items of the region, on the basis of museum collections: note that these showed objects in isolation, without any person using or wearing them. Akerman, Birch, and I then showed these photos to Iwaidja speakers to elicit the terms for these objects, where still known. In many cases, verbs rather than nouns were preferred as responses to these photos:

(a) Photos of bracelets or arm bangles were described by the verb dangkardakbung, lit. '(s)he wears it on his/her arm', though the reference to a particular person implied by the English term is misleading, ${ }^{18}$ so that a better translation might be '(something that) one wears on one's arm'. Further questioning revealed that this term could also refer to a watch. (There is in fact a nominal term, barnda 'bangle', which eventually came up, but this was not the first term given.)

(b) Loincloth: wilakbin 'he wears it tied around his loins'. No directly corresponding nominal term was provided, though the Kunwinjku loanword manburrba 'cloth' is often used to denote a sarong.

(c) Belt: the term ruwurlakbang 'he has it around his waist' was volunteered. Again, there appears to be no corresponding general nominal term, though the term kurlawurr can be used with the more specific meaning of 'ceremonial tasselled belt'.

(d) Headband: the term kardakbin '(s)he wears it around his forehead ${ }^{19}$ was used. Again there is no corresponding general nominal term, though there is a term marraldaka which refers to 'ceremonial headgear'.

(e) Necklace: speakers volunteered the term barluriny 'he has it tied around his neck'; this could also refer to someone with a hangman's noose around their neck. There is no corresponding nominal term.

In all of these cases, then, the favoured and sometimes the only construal was in terms of the action of putting on or wearing, rather than the entity itself. Though wearing verbs are known for some other languages of the world (e.g. Korean, Japanese), they had not previously been reported for Australian languages. Moreover, none of these had been recorded in the Pym and Larrimore draft dictionary (containing 1,605 entries) which was the only record of Iwaidja vocabulary before

${ }^{18} \mathrm{Cf}$. Evans (2002b) on the fact that pronominal affixes in many head-marking languages need not be anaphoric.

${ }^{19}$ Incidentally, this term then allowed us to understand the composition of the term for a detachable harpoon head, kardakbikbin (with iterative right reduplication of $-k b i$ ), which can be seen to be a metaphor based on the way the rope of the detachable harpoon head is wound around the head of the harpoon shaft) 
the project-nor had Bruce Birch or myself recorded any of these forms before the joint field trip with Kim Akerman. (The two joint field trips with Akerman threw up many additional verbal terms which space prevents me going into here. One of the reasons was that, as a craftsman himself, his first engagement with any new item of material culture was to start trying to replicate the processes of manufacture and use, which he knew about from being able to make similar objects. Iwaidja speakers-in every case accomplished craftsmen or craftswomen themselvesresponded to Akerman's craft expertise immediately and began to demonstrate relevant techniques or tricks, throwing up further vocabulary (cf. Birch 2006).)

(ii) Tide terms. The phasal, processual nature of tides does not prevent them from being lexicalized as nouns in English (then combinable with verbs like 'come in/up' or 'go out'). However, Iwaidja uses verbs for all tide terms, as in (5). This suggests that Iwaidja construes tides as processes (e.g. of the sea moving over the sea bottom/beach) rather than as the time at which a particular point is reached, indicated by the etymology of English tide as meaning 'time', as the Dutch and German cognates (tijd, Zeit) still do.

(5) Ma-na-nga-yambu-ng kuburr.

3veO-FUT-3fA-tide.be.full-NPst tomorrow

'The tide will be really full tomorrow.'

A sample list of Iwaidja tide verbs is given in (6) below. Note that some of these terms employ 'frozen' gender prefixes for subject and/or object (given here in square brackets), a topic I defer until §8.4.2.

(6) ldakbarlarlan 'tide come in'

ldakirrinirra 'tide come in gradually'

ldawurtin 'tide come up'

[inyju-] urdurrikun 'come in, of neap tide'

[manga-Iyambung 'be king tide, be really full tide'

ijbalmalbakbakbany karlda 'tide be right out, of low spring tide'

yaburnalkan 'tide go out'

awunduhulmurndanymin 'be full tide'

arawurdin mambal 'be spring tide'

A few of these terms were already known from Pym and Larrimore's draft dictionary. ${ }^{20}$ Birch had begun collecting some of these terms during the first phases of the

${ }^{20}$ Pym and Larrimore had listed them as nouns: the part of speech categorization used in their electronic dictionary didn't allow for deverbal nouns, and in any case some of the lexicalized prefixes can throw analysts off the track here. In their sketch grammar of Iwaidja, Pym and Larrimore (1979: 58-9) include a brief discussion of problematic lexemes which take verbal morphology but which 'ar used as nouns with their own meaning', such as rimuni 'thunder' (lit. 'he hits it') and wurtiyin manyij 'sunset' (lit. 'the sun dives into the water'), though they do not extend this discussion to tide term.
DoBeS project, but again, it was only when Akerman joined us for joint fieldwork that most of the set emerged-in this case not because they are material culture items, but because of his experience doing other fieldwork (oriented to maritime technology) with other Aboriginal groups (e.g. Bardi) in areas with prominent tidal variation.

\subsubsection{Are situations often described using highly specific denotations} that incorporate reference to entities as well as processes?

A third aspect of Iwaidja's lexical style is the large number of verbs which have semantically inherent arguments', i.e. entities which must be included in the semantic representation of the verb's meaning but which do not form syntactically visible arguments (and which would not normally be represented by NPs in clauses containing these verbs).

This is most evident in the many verb classes which incorporate reference to a body part:

(a) Wearing verbs (see \$8.4.1.2(i) above), e.g. 'wear on arm or wrist'. As mentioned above, these terms were almost all gathered during joint fieldtrips with Kim Akerman to work on material culture.

(b) Washing verbs, e.g. wudbinybun 'wash face', yijbalwinybukbun 'wash hands', (d)angkadbinybun 'wash arms', ngartbinybun 'wash hair', ldahalwinybun 'wash feet', ldakbalwinybun 'wash lips'; these terms were gathered in the course of regular fieldwork.

(c) tying up verbs, e.g. angkadburang 'tie (turtle) up by front fin', angkarrakbun 'tie armlet on arm'; these terms were gathered during regular fieldwork.

(d) Posture verbs, e.g. wartbalman 'lie with forearm across or resting on forehead', gathered during regular fieldwork.

(e) Pain verbs, e.g. ambudbunya 'have a burning pain in one's chest', ambudbarrki 'have a sharp pain in one's chest', ambudbanbun 'have a biting pain in one's chest'. Most lexemes in this set were elicited by Sabine Hoeng during preparation of an Iwaidja medical phrase book to help visiting medical personnel communicate with Iwaidja-speaking patients.

(f) Painting verbs, e.g. wudbirrawukbun 'paint face', amburrardbanjin 'paint chest', ngarndalmirrawun 'paint wall of shelter'. Most of these lexemes were elicited by Sabine Hoeng while investigating art vocabulary on a spin-off project on Aboriginal artists of the Cobourg region.

These examples show there is a clear 'semplate' or 'semantic template' (Burenhult and Levinson 2008b) for characterizing actions in terms of involved body part loci,

However, the ability of such terms to inflect for future tense (5), as well as the full panoply of verbal inflections (subject, object, direction), clearly marks them as verbs. 
i.e. for specifying the body part which the action is directed at or affects. I return to the importance of this for the morphological analysis of Iwaidja verbs in §8.4.3.

\subsubsection{Are there situations where verbal expressions get drawn upon, apparently as circumlocutions indexing the social context of the utterance?}

All the examples so far have focussed on the denotational aspect of meaning. However, contextual aspects - by which lexical choice indexes aspects of the situation of utterance, particularly the relationships between speaker and hearer-may also play a key role in shaping lexical and grammatical structures.

In many Australian languages this insight is particularly evident in the formulation of kinship expressions, which are shaped not just by the relation between the 'anchor' or propositus and the referent, but by the adjudication between, and recognition of, the fact that the referent may be kin to both speaker and addressee. The question of which speech act participant to choose as anchor may be pragmatically delicate, so much so that many languages have developed expressions that simultaneously relate the referent to both participants, through various formulations, or otherwise obscure the choice.

Consider the expression 'Mary's aunt Joan': 'Mary' is the anchor and Joan is the referent, with the two-place logical relation 'aunt_of $\mathrm{X}, \mathrm{Y}$ ' holding between them producing such an expression in English is straightforward. Now imagine you are Mary, and that I am your mother, with Joan being my sister. In English I have a range of alternatives: I could refer to her as 'auntie Joan' or 'your auntie Joan' taking your perspective implicitly or explicitly, and leaving my own relationship to her (and you) out of explicit account. I could also refer to her as 'sis' or 'sister Joan', though this would sound pragmatically odd, largely because it is unusual for senior speakers to adopt their own perspective over that of their juniors. But what is not available to me in the grammar or lexicon of English, or of other European languages, is a way of referring to her from both perspectives at once, with a term that means something like 'the one who is your (maternal) aunt and my sister, me being your mother' (about the nearest would be to say 'our Joan', but this would then omit any overt kin term).

Methods for recording kin terms through the so-called 'genealogical method' pioneered by W. H. R. Rivers (1910), and employed during the famously interdisciplinary Cambridge Expedition to the Torres Strait, project this English downplaying of contextual factors into the elicitation of kinship terms, by not treating speaker-addressee kinship relations as one of the factors that needs to be investigated within the domain of kinship terminology.

Since the early 1980 s Australianists have uncovered a number of languages whose systems of kinship terminology do index speaker-addressee, i.e. interactional, relations through systems of so-called 'triangular' or 'trirelational' termsLaughren (1982), McConvell (1982), Merlan (1989), Garde (2002), and Evan (2003). Lea (2004) has reported a very similar system in the Amazonian language Mẽbêngôkre. One object of our research was therefore to see whether Iwaidja had such a system, and if so to document the relevant lexical terms. Note also, before continuing, that in some circumstances it is possible to represent the 'triangle' of kin reference in context through a two-place verb: this is straightforward if one relation is siblinghood (e.g. 'our mother', where speaker and addressee are both children of the same mother) but can also be achieved, more obliquely, by appealing to other shared properties (e.g. both being in the same lineage) that can be reflected in conventionalized terms, as we shall see with the term arrambadbi below.

Even knowing what to look for, though, does not necessarily make it easier to find: asking speakers of Aboriginal languages if they have terms that mean things like 'the one who is my daughter and your mother' never, in my experience, turn up the sort of lexical items one is looking for. Initially (in our 2004 field season), we therefore adopted a strategy that built on linguistic anthropologist Murray Garde's own expertise in the very elaborated trirelational system of Bininj Gun-wok, known in that language as Kun-derbi, Gun-dembui, and other dialect-specific variants. Since most Iwaidja speakers also speak excellent Bininj Gun-wok, it was possible for him to work by giving examples of Kun-derbi terms and asking speakers how they would express them in Iwaidja-and in fact it turns out that Iwaidja does have a number of such terms, in a register known in Iwaidja as kundeybi.

The name of this register is a clear Bininj Gun-wok loan, though the actual terms within it are all indigenous to Iwaidja. Once we had a few examples, speakers then got the hang of our line of enquiry and began to furnish other items. (Note, methodologically, that in effect this took the expertise that Garde had developed in another mutually known language of the region through participant observation, then proceeded to use it as an initial source for translation-based elicitation, but where the elicitation language is much closer in structure to the target language than English is. Later on, as Birch developed fluency in Iwaidja, new Kundeybi terms have turned up through direct participant observation in Iwaidja.)

Of the seven Kundeybi terms that were collected by late 2008, two are verbal in form.

The form arrambadbi is used precisely in the Mary-and-Joan scenario outlined above: it would be used by a woman speaking to her daughter about someone who is the speaker's sister and the addressee's (maternal) aunt. Analytically, it combines a vowel-harmonized ${ }^{21}$ form of the prefix $\operatorname{arrumb}(u)$ - 'he/she/they $>$ us' with the

${ }^{21}$ It is not currently clear why the second vowel gets harmonized in this word, but it may reflect ongoing conventionalization of the word as a gestalt-which would of course lead to it ultimately 
verb root $a d b i$ 'find', thus in this context '(the one such that [someone (to wit, my mother)]) found (conceived) us (i.e. myself and her [and on to you in the next generation] $) \cdot{ }^{22}$ Other prefixal combinations with this verb are also possible.

The second verbal form, yarrunan, is used by a woman to someone she calls ngawiny 'patrichild; child through the male line, i.e. brother's child for a woman's speaker', in referring to someone else she calls ngawiny, who would therefore be a sibling of the addressee. Formally, this combines the prefix yarrun- 'you singular > us; you plural > me, us' with the verb root an 'spear'; at present the motivation for this locution is not understood.

Two general points arise from these examples. First, the role of a linguistic anthropologist (Garde) in the team was crucial in breaking into this problemfor the dual reasons that (a) by his disciplinary training he took an approach that did not bracket out the contribution of interaction to verbal formulation, and (b) prolonged participant observation while learning to speak a related language fluently enabled him to understand a system that can easily slip by unnoticed if one takes a denotationally focussed inquiry as starting point. Later this was followed up by Birch, who, as the investigator who spent most time in the field and has gained the most fluency in the language, was best placed to apply participant-observational methods in Iwaidja itself

Second, there are interesting reasons why verbal terms seem to play an important role in the system of triangular kin terms. Partly this seems to follow from the fact that verbs can index referent sets (subject and object), which combined with the subset-reference principle mentioned above allows relationships to be constructed as reflecting a common standpoint on the referent. But they also seem to reflect a method of describing kin relationships that uses abstract metaphorical extensions of verbal terms ('find', 'spear') to construct the rather ineffable shared relationships that can then be expressed as holding with respect to the referent, jointly, between both speaker and addressee.

becoming a deverbal noun, rather than a verb proper. For the moment its treatment as a verb (albeit with the above irregularity) is warranted by the existence of other prefixed forms (kudnadbi, yadnadbi, etc.) which behave regularly in terms of their verbal prefixes.

${ }^{22}$ The fact that the inclusive/exclusive distinction is neutralized in objects of transitive combinations nicely allows an implicit extension from 'found us <exclusive>' i.e. my sister and me, to 'found us <inclusive>', i.e. my sister, me, and on to you in the next generation. Note also that the technique of referring to one member of a subset by a prefix denoting the superset is widely used in kinship expressions-e.g. awunbani, lit. 'they two sit (i.e. live together)' can refer either to a pair (husband and wife) or using the subset reference method, to just one member of the pair, i.e. 'the one such that they two live together'. If anything it is even mor widespread in $k$ undephi expresions, where it achieves an approprate balance of vagueness and inclusiveness.

\subsubsection{Lexicalized gender agreement}

As mentioned in $\$ 8.3 .2$, when we began the DoBeS project it appeared that Iwaidja had jettisoned most of the morphology associated with a five-way gender contrast in proto-Iwaidjan, and still preserved in Mawng. However, a number of obscure verbs-again mostly thrown up by interdisciplinary fieldwork- have shown that far more of the proto-Iwaidjan gender agreement prefixes on verbs have survived than we originally thought. These relics are difficult to detect, however, because of the highly lexicalized and non-productive nature of some parts of the Iwaidja prefix paradigms.

Often these are limited to a single verb-what Singer (2007) has called 'lexicalized verb agreement', rather like a verb + noun idiom (kick the bucket) except that the fixed element is a pronominal prefix of fixed gender, rather than a noun (see §8.3.2). To get an impression of what has happened with Iwaidja, imagine that English had just kept he and she as $3 \mathrm{rd}$ person subject pronouns (shedding it and they) and just kept ' $m$ as object pronoun-except that a few verbs can only use it as subject, regardless of the referent, and a few others can only use ' $m$ as object, again regardless of the referent.

If there is just a single verb with a particular prefixal combination, of course, segmentation is difficult to justify since there are no recurring partials, which then makes it hard to demonstrate whether the word should be treated as a verb rather than a deverbal nominal. Luckily, however, the issue can usually be clinched by seeing if there is a future form, since the future prefix -(a)na-is generally placed between prefix and root.

To illustrate, here are three examples of previously unattested gender prefixes with lexicalized verbs.

\subsubsection{1 ang- as intransitive subject}

In Mawng, this gender form denotes what Singer (2007) called the 'land and liquids' gender. Pym and Larrimore (1979) refer to this prefix occurring in the object slot of a score or so of transitive verbs generally associated with 'earth' or 'ground', but do not mention the possibility that it can also represent intransitive subjects.

However, a (so far unique) example of this came up during the musicological part of the project, which brought in the collaboration of Linda Barwick. In one of David Minyimak's songs in the Jurtbirrk genre (see Barwick et al. 2005; Barwick et al. 2007), he uses the verb angmarranguldin (segmentable as ang-plus -marranguldin). Interpretive discussion of this verb with a range of speakers, and elicitation of further contexts, showed that it refers to particular meteorological conditions (e.g. lightning, wind) that bring back memories associated with a place from which sensory cues are transmitted by the weather conditions. Examples 
would be the smell of a wind changing as one sits on a beach, or the sight of a place burning after being struck by lightning. The semantic motivation for the angprefix on this verb appears to be that it is the place or 'country' that is the source of the emotion felt by some affected person-a feeling summed up in the title of Xavier Herbert's novel Poor Feller My Country. As discussed in Barwick et al. (2007), many Iwaidja terms for the subtler nuances of the emotional palette appear rarely if ever in normal language but turn up with much higher frequency in the poetic register of song language, tuned as it is to feeling and interiority.

8.4.2.2 manga- [vegetable object + feminine subject]

Earlier work, since Pym and Larrimore (1979), had isolated both a vegetable object prefix $m a$ - and a feminine transitive subject prefix $n g a$ - in restricted contexts: for example, the nga-prefix only turns up in a tiny corner of the paradigm, for the combination ' 3 sg feminine subject acting upon 3 sg object'. ${ }^{23}$

From these forms one would predict the existence of a form manga-: 3sg. fem $\mathrm{A}>3$ veg.O; normal morpheme order is $\mathrm{OA}$-if both are 3 rd person. But the non-productive nature of the Iwaidja verb paradigm means that many theoretically possible combinations appear simply not to occur: normally, for example, if one puts a feminine subject with a verb taking a ma-object this would be expressed not with manga-but with mambu-, which etymologically is maN- (3fem object with a nasal object marker that has elsewhere disappeared) and bu- (3pl subject marker)

Mawng attests this combination, e.g. in the verb ma-nga-niking 'she is carrying (it: vegetable) firewood' (Singer 2007: 99), and I had tried making up verbs using this combination, but had met with no success, except for people saying things like 'sounds like you're trying to speak Mawng, but it would be wrong in Mawng anyway!'

When intensive questioning by Kim Akerman about tide terms extended our vocabulary in that domain, however, a word with just this prefix turned up: mangayambung ( 7 ) means '(it is) a king tide, a really full tide'. (The etymological motivation for these lexicalized gender prefixes may lie with a conceptualization like 'it (sea/current/wave [fem.] lifts it (seaweed: veg.) high up onto the beach' or some such.)

(7) ma-nga-yambung

3sg.v.O-3sg.f.A-be.high.tide

'It is a king tide'

On first hearing this term, it was not completely clear that it was a verb, rather than (for example) a noun compounded with the root manga 'throat'; but checking

${ }^{23}$ And even there it is heavily disguised, with the combination $3 \mathrm{sgFemA}>3 \mathrm{sgO}$ normally appearing on the surface as $k a$-, underlyingly $K$-nga- where $K$ represents the hardening effects of a 3 sg object on the following consonant (Evans 1998). revealed a future form manangayambung ((6) above) which clinches its verbal status, since the future prefix is restricted to verbs.

So far this is the only word we have recorded with this particular prefix combination.

\subsubsection{3 inyju- [feminine object iny-plus allomorph}

ju- of 3 pl transitive subject bu-]

Feminine transitive subjects in $n g a$ - have been attested for Iwaidja since Pym and Larrimore (1979), as mentioned in the previous section. But until our joint work with Akerman there had been no attested occurrences of the corresponding feminine absolutive prefix iny-, known from Mawng and Ilgar. Once again, though, an example popped up in the specialized vocabulary of fire tools: the expression for rubbing or twirling a firestick takes the verb $w u$ - 'hit/impact upon' and combines it with an object prefix of form iny- (reduced to $n y$-by vowel coalescence after the 1sg transitive subject marker $a$-), as illustrated in (8). Here the etymological motivation for the use of the feminine object marker appears to be the commonly employed sexual symbolism in which a firedrill (conceived as a masculine part) enters and creates heat in a receptacle (conceived as a feminine part), hence 'hit/ impact upon (a feminine object)'.

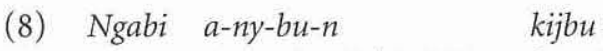
1sg 1sgA-3femO-hit-NPst firestick

'I am rubbing the firestick.'

Again, this is the only word we have recorded with this particular prefix combination

\subsubsection{Lexicalized gender agreement: summary}

As these three examples illustrate, the atrophy of the inherited proto-Iwaidjan prefix paradigm, which productively combined five subject genders with five object genders,${ }^{24}$ into the reduced Iwaidja prefix paradigm did not wipe out as many cells as previously believed. It now looks as if some cells in the paradigm have managed to survive in combination with just a single verb-a finding of great interest to our understanding of how paradigms wax and wane. But each of the three new cells reported on above only came to light as a result of the sorts of multidisciplinary lexical probing outlined above.

${ }^{24}$ Well, almost- - there is no evidence from any Iwaidjan language of combinations with any of the 3 non-human genders as transitive subject; see Evans (1998) and, for the Mawng paradigms, Capell and Hinch (1970) and Singer (2007). 


\subsubsection{Segmentability of verb stems}

In \$8.3.3 I stressed the difficulty of making sense of the many long, apparently unsegmentable verb stems in Iwaidja. Then, in \$8.4.2, I illustrated how subsequent collection of verb vocabulary has revealed that many verb stems have specific bodypart locus meanings.

Assembling the verbs discussed in $\$ 8.4 .2$ and sorting them by the body part involved has enabled us to identify many 'corporeal prepounds'-recurring first elements of verbs where a recurring form correlates with a recurring meaning. Here are some examples:

(9) dangkardakbung 'wear on arm or wrist' angkarrakbun 'tie armlet on arm'

angkadburang 'tie (turtle) up by front fin'

$(d)^{25}$ angkadbinybun 'wash arms' (cf. winybun/binybun 'wash')

Recurring element: (d)angkad (d)angkard angkarr 'arm, forefin'

(10) ambudbunya 'have a burning pain in one's chest' (cf. wunya 'burn')

ambudbarrki 'have a sharp pain in one's chest'

ambudbanbun 'have a biting pain in one's chest' (cf. manbun 'bite')

Recurring element: ambud / amburr 'chest'

(11) ldakbalwinybun 'wash lips' (winybun 'wash')

Residual element: ldakbal 'lips, mouth'

with some additional evidence for ldak 'mouth' e.g. ldakburran 'have in one's mouth'

For most of these elements the corresponding free-form body part term is formally unrelated: cf. (d)angkad 'arm' (9) with the semantically equivalent noun root mawurr 'arm'. But for some others it is possible to find resemblant forms: an example is the noun root for 'chest', amburryak 'chest', clearly related to the verbal element ambud-/amburr- 'chest'.

Likewise the second element is sometimes independently attested as a verb in its own right (e.g. winybun 'wash', wunya 'burn'), but in many other instances it is not (e.g. warrki $\sim$ barrki)

It now appears that a once-productive $\mathrm{N}_{\mathrm{bp}}+\mathrm{V}$ compounding strategy of the Bininj Gun-wok type has become frozen, leaving body part morphemes marooned inside the verb stem. Sound changes have increasingly disguised their form, and introduced formal variation making the signifier harder to parse. At the same time, lexical changes have replaced many of the (presumed) original nominal lexemes with new lexemes unrelated to the prepound form. This is the most likely

${ }^{25}$ A small number of Iwaidja verb stems have initial $d$ s that are only found with a limited set of pronominal prefixes (basically comprising an initial subject element plus an object element ending in $K)$. The most likely historical scenario is that the $d$ is original and has been lost in all but this environment (Evans 2006b). explanation of why the Iwaidja verb-stem structure is so much more opaque than those found in Bininj Gun-wok.

Working from the much larger corpus of verb stems that we have now, thanks in good part to the expansion of specialized lexical forms that interdisciplinary work produced, we have been able to analyse a large number of Iwaidja verb lexemes into the following form (see Teo 2007 for detailed evidence)

\section{(12) Body.part.prepound + stem}

This morphological analysis only became possible once we had a large enough verb vocabulary to attest multiple instances of the same prepound. By bringing the morphological verb structure into line with that of its neighbours to the south, it has set the scene for the next stage of comparative research, which will be to compare $\mathrm{N}+\mathrm{V}$ compounds between Iwaidjan and Gunwinyguan languages.

\subsection{Conclusion}

I have stressed how most of the verbs discussed above came to light through interdisciplinary fieldwork. This is not to say they wouldn't eventually have surfaced anyway, given enough linguist-in-field-years or a large enough corpus, or omniscient lexicographers who know, as Sir James Murray well illustrated when he compiled the $O E D$, to ask about everything. But the fact is that, within our own project, it was the interdisciplinary work that was crucial in bringing most of these verbs to light: structures that had not yielded to front-on linguistic attack were prised open through interdisciplinary work that came around the side. At a certain point, of course, once patterns start to emerge we can start to play with them in the way linguists excel at, making up new combinations which we guess might occur. But typically this does not begin to happen until we have at least some combinations to start with.

Returning to semantic typology, a fundamental and still unanswered questions is: are some semantic domains more variable cross-linguistically, and if so which?

It is a good bet that event descriptions are one of the most variably lexicalized domains. Yet we won't be able to test this hunch properly until we have extensive cross-linguistic data for the verb lexicon that is comparable in detail to that for the nominal lexicon. My experience across a range of fieldwork projects is that this is going to depend on a whole range of interdisciplinary collaborations-as varied as 
the realms of knowledge that any language can represent ${ }^{26}$ - which greatly broaden the situations in which language in use can be encountered and noted.

${ }^{26}$ For the sake of narrative unity I confined myself in this paper to data arising from the Iwaidj project. But to broaden the argument using examples from other projects, here are some other examples (all verbs) from interdisciplinary work conducted myself or by close colleagues on other Australian languages: (a) Kayardild verbs I only became aware of under the pressures of doing translation or interpreting in legal contexts: these included the difference between two causatives which I had been fruitlessly trying to elicit for years, but which cropped up when speakers pointed out that I used the wrong one (yulkaanmarutha rather than yulkalutha for 'make permanent, for ever') in the context of a native title handover claim because 'they're only giving us the paper, then we have to trust that', i.e. the purported causation of permanence was mediated rather than direct. Also throug interpreting for lawyers, I discovered a relict applicative suffix -ri-as attested in the verb biyarija 'paddle [a canoe] with [water supplies]', when a lawyer asked me to ask whether people knew enough about the water supplies available on an island to take baler shells of water with them on their canoes when they visited

(b) another example of specialised vocabulary that only arose from transcriptions of Bininj Gunwok songs from the Nabarlek song cycle in work with Murray Garde, Allan Marett and Linda Barwick on the Western Arnhem Land Endangered Song Language Project, is the rather gruesome verb ngalwowme 'drown out the death cries of someone being killed by making camouflaging noises over the top'

(c) verbs of specific choreographic movements in Murrinh-patha, like wintijrdum 'while dancing drop on one knee with one hand up one hand down and head bowed for a moment after that (most likely with a woomera)', that arose during the investigation of Murrinh-patha song texts by a team comprising linguist Michael Walsh and musicologists Linda Barwick and Allan Marett; Walsh suggests that compressed song texts favour the appearance of such words because of they way their brevity allows 'semantic density', like a small dessert or liqueur, highly specific tastes can be processed (Walsh 2007:132)

Examples like these, which could readily be multiplied, emphasise that the cases treated in the present paper are just the tip of a very large iceber
C H A P T E R 9

\section{UNDERSTANDING HUMAN RELATIONS (KINSHIP SYSTEMS)}

\section{LAURENT DOUSSET}

\subsection{INTRODUCTION}

Kungkankatja, minalinkatja was the answer of an elderly man to my question, 'How come you call your cousins as if they were your siblings?', when I expected to hear different words, one for sibling and one for cousin. This episode occurred at a very early moment of my initial fieldwork in the Australian Western Desert; certainly early enough to set the stage for some investigations into the complex nature of people's own (emic) views of the idea of human relationships, while considering them against the structure of universal (etic) typologies of the human family. Kungkankatja, minalinkatja, literally 'from a woman, from a man', meant in the context of my question that the children of a woman and those of her brother are to be considered identical. Although I shall not go into the analytical details of this particular example (see Dousset 2003; 2005), it will nevertheless provide us here with some elementary guidelines for the conducting of linguistic investigations 